NOTE

\title{
Remotely releasable instruments for monitoring the foraging behaviour of pinnipeds
}

\author{
Russel D. Andrews* \\ Department of Zoology, University of British Columbia, 6270 University Blvd, Vancouver, British Columbia V6T 1Z4, Canada
}

\begin{abstract}
The use of stomach temperature data loggers to record prey ingestion has proven to be very valuable when combined with time-depth recorders and satellite tracking devices in studies of seabird foraging ecology. This paper presents a similar system that will allow biologists to determine the precise timing and location of foraging by pinnipeds. The system includes a stomach temperature transmitter and an animal-mounted instrument package. The instrument package contains a satellite transmitter, for remote tracking of movements, and a data logger, for recording dive depth, swim speed, water temperature, and stomach temperature (made possible by an incorporated telemetry receiver). The instrument package can be remotely released upon command to allow data recovery without animal recapture. The system was tested on 6 Steller sea lions Eumetopias jubatus in Southeast Alaska and found to be a powerful tool for quantifying foraging behaviour, although some suggestions for improvement are presented.
\end{abstract}

KEY WORDS: Stomach temperature - Prey ingestion - Data logger - Remote release - Telemetry - Remote monitoring . Steller sea lion

Advances in remote monitoring instruments have recently facilitated a rapid increase in our knowledge of the foraging behaviours of many pinnipeds. Satellite tracking devices and time-depth recorders (TDRs) allow investigators to monitor beyond visual range as animals migrate out into the open ocean and dive beneath the surface, but these techniques do not provide direct evidence of foraging. Most investigators have primarily inferred foraging behaviour from the shape of time-depth profiles and movements at sea. As early as 1964, however, an attractive method for determining the precise timing of marine mammal prey ingestion was proposed by Mackay (1964). This method relies on the drop in stomach temperature that occurs when a relatively warm animal ingests much

•E-mail: andrews@zoology.ubc.ca cooler prey, a result that has been shown to occur in various captive marine mammals (Mackay 1964, McGinnis et al. 1972, Ohata et al. 1972, Whittow et al. 1974, Gales \& Renouf 1993). Mackay suggested a method for recording the transmissions of a stomach temperature transmitter by using an animal-mounted recorder (Mackay 1964), and later a method for recording dive depth was also proposed (Mackay 1966). Specific details of a similar system were published in the mid-1970s (Norris et al. 1974, Wartzok et al. 1975), but only recently has the method of stomach temperature monitoring been applied to study the foraging behaviour of wild marine animals.

Initial applications of stomach temperature monitoring to determine prey ingestion in free-ranging marine animals utilised ingested stomach temperature data loggers as opposed to transmitters (Wilson et al. 1992, 1998, Tanaka et al. 1995). This technique has been successfully applied to loggerhead sea turtles and at least 19 species of seabirds, but, as Wilson et al. (1998) pointed out, its major disadvantage is that regurgitation of the data logger results in a complete loss of data. Many species of pinnipeds regularly ingest and regurgitate rocks (Emery 1941). Therefore, to study pinniped prey ingestion it would be better to remotely record the transmissions of a stomach temperature transmitter in order to ensure that the data collected before regurgitation are not lost with the ingestable device. Bjørge et al. (1995) used this method to determine the timing of prey ingestion by harbour seals, but their use of a shipmounted receiver to monitor the transmissions of an ingested stomach temperature ultrasonic transmitter is very labour intensive and may not be suitable for most studies of pinniped foraging. Given that most studies of this type already incorporate some type of animalmounted device, a TDR modified to incorporate a telemetry receiver as suggested by Mackay (1964) would be a good alternative to tracking with a ship. 
Archiving data on the animal has the disadvantage, however, of necessitating recapture. Recapture of some pinnipeds is only possible at certain times of the year, for others it is always very difficult, and in general the stress of recapture is probably better avoided. Satellite telemetry is a good method for retrieving data from TDRs, but the state of data compression techniques and the limited data transmission rate allowed by the most accessible satellite system (Service Argos) currently exclude the possibility of satellite-linked stomach temperature recorders. Another alternative to animal recapture is the use of buoyant, self-detaching recoverable recording units (Mackay 1964), which have been used to study the diving behaviour of a few marine mammals (Ellis \& Trites 1992, Baird \& Goodyear 1993, Westgate et al. 1995). Not knowing the exact time of release is inconvenient, however, and the value of such units would be greatly enhanced if the release could be triggered by the investigators when they are ready to recover the unit. This paper describes a new system that includes this innovation for monitoring the foraging behaviour of pinnipeds. The system includes a stomach temperature transmitter and a data logger with a built-in telemetry receiver so that it can record stomach temperature as well as dive depth, swim speed and water temperature. The data logger is part of a remotely releasable animal-mounted package that also contains a satellite transmitter for remote tracking of movements.

Stomach temperature transmitter. The stomach temperature transmitter (STT) and receiver were modified from a human heart rate transmitter system (Polar Electro, Port Washington, NY, USA). An electrocardiogram (ECG) R-wave simulator, consisting of a 555 timer (National Semiconductor, Santa Clara, CA, USA) and a temperature-compensated circuit, produced an output signal whose pulse rate varied only with the temperature at the sensing thermistor (Thermistor Model 112105PAJ, Fenwal Electronics, Milford, MA, USA). The simulator output was connected to the inputs normally used for an ECG on the R-wave-detector/transmitter (Polar Transmitter PC Board). Upon each detection of a simulated R-wave the Polar unit transmitted approximately 36 cycles of $5 \mathrm{kHz}$ sine waves, producing a pulse interval modulated temperature transmitter. The STT was powered by one $3.6 \mathrm{~V}$ lithium AA cell (LS14500, SAFT, Romainville, France) with a capacity of $1.9 \mathrm{Ah}$ at $3.6 \mathrm{~V}$, providing nearly $100 \mathrm{~d}$ of continuous operation at $37^{\circ} \mathrm{C}$. The entire assembly was cast in rigid epoxy resin (Sealtronics, Industrial Formulators, Burnaby, BC, Canada) in a cylindrical shape $45 \mathrm{~mm}$ diam. $\times 65 \mathrm{~mm}$ long). The sensing thermistor was located on the inside surface of a $15 \mathrm{~mm}$ wide titanium ring that ran along the outside edge midway along the STT's length (Fig. 1). STTs were calibrated in a con- stant temperature water bath over the range of 5 to $40^{\circ} \mathrm{C}$ using a National Institute of Standards and Technology (NIST)-traceable thermometer with $0.05^{\circ} \mathrm{C}$ gradations. Over the temperature range of 20 to $40^{\circ} \mathrm{C}$, the STT pulse rate typically varied non-linearly from approximately 400 to 1000 pulses $\mathrm{min}^{-1}$. Counting the number of pulses received in a $10 \mathrm{~s}$ period allowed for a resolution of $0.2^{\circ} \mathrm{C}$ at $30^{\circ} \mathrm{C}$, and the absolute accuracy was $\pm 0.2^{\circ} \mathrm{C}$.

Data logger. The data logger was based on an offthe-shelf computer (Tattletale Fast Lite, Onset Computer Corp., Pocasset, MA, USA) and was customised to monitor the following variables: dive depth, swim speed, ambient temperature and stomach temperature. The design was similar to a device built for study-

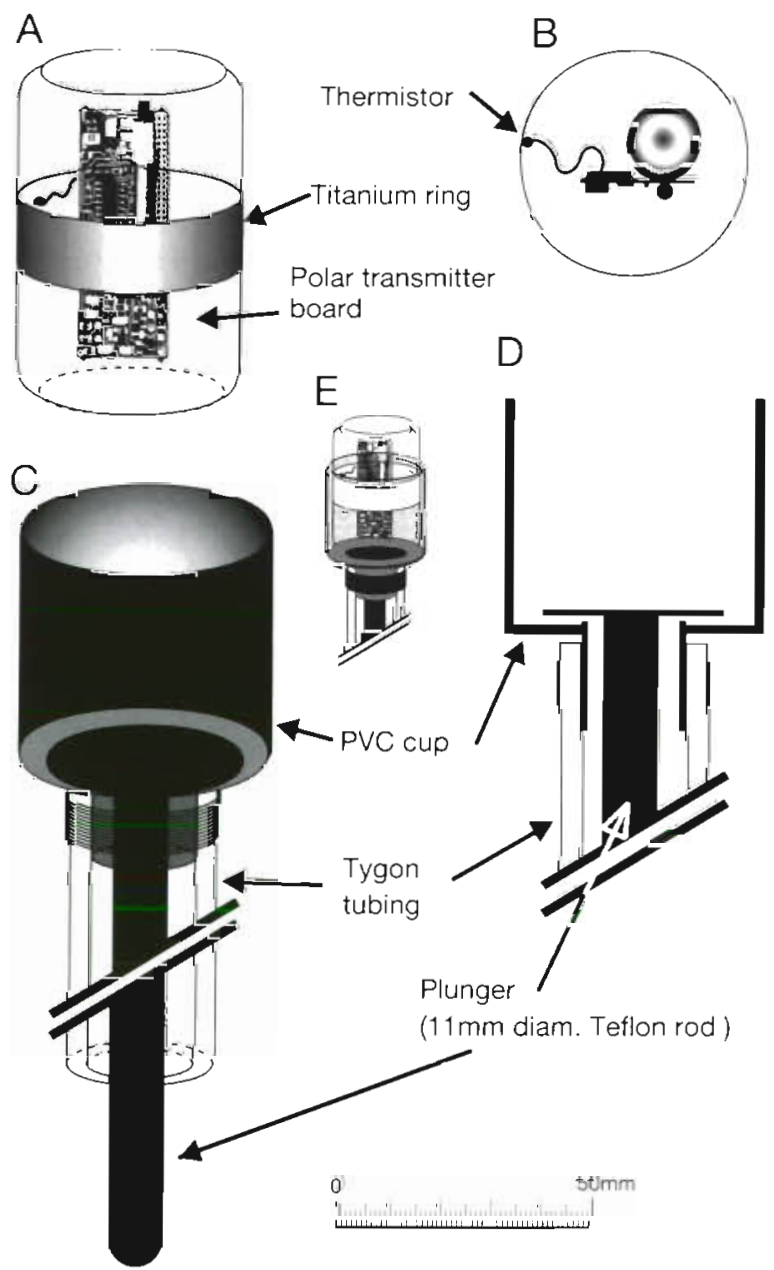

Fig. 1. Schematic diagrams of $(A, B)$ the stomach temperature transmitter (STT) and (C, D) the STT insertion device in profile $(A, C)$ and cross-section (B) or longitudinal section (D). ACtual length of the insertion device's tubing and rod is $1.5 \mathrm{~m}$. The STT is placed in the cup of the insertion device ( $E$, not to scale) and passed down the esophagus; upor reaching the stomach, the STT is ejected by pushing the plunger from the opposite end 
ing elephant seal diving physiology (Andrews 1998), so only the variations and essential details will be presented here. Depth below the surface was sensed by a 0 to $5 \mathrm{MPa}$ pressure transducer connected to a proprietary signal conditioning circuit (Model PA7-50, Keller PSI, Hampton, VA, USA), providing a resolution of $1.4 \mathrm{~m}$ of seawater over the range of 0 to $300 \mathrm{~m}$. Swim speed was transduced using a magnetised turbine (Flasch Electronics GmbH, Dachau, Germany). Ambient temperature was sensed using an epoxy-encapsulated thermistor (Fenwal Model 587-59MM09) connected to a signal conditioning circuit that provided a resolution of $0.2^{\circ} \mathrm{C}$, with an absolute accuracy of $\pm 0.2^{\circ} \mathrm{C}$.

The transmissions of the STT were received by a circuit board (Polar OEM Receiver PC Board) that included a coil antenna and a circuit that converted the $5 \mathrm{kHz}$ bursts into $10 \mathrm{~ms}, 3.0 \mathrm{~V}$ square-wave pulses that were fed into 1 of the computer's digital count channels. Whether in seawater or air, the range of the STT was about $1 \mathrm{~m}$ when the transmitter's coil antenna was approximately parallel to the receiver's coil antenna, but otherwise was less than $0.3 \mathrm{~m}$. Therefore, 2 receiver boards were electrically connected in parallel and physically placed at right angles to one another to ensure that the range of the transmitter was less dependent upon the orientation of its antenna.

Most of the sensor circuitry was assembled on a single printed circuit board stacked $8 \mathrm{~mm}$ below the Tattletale Fast Lite computer board. The data logger was powered by two $3.6 \mathrm{~V}$ lithium AA cells (SAFT LS14500) in series, with a capacity of $1.9 \mathrm{Ah}$ at $7.2 \mathrm{~V}$. The entire data logger assembly was cast in Sealtronics epoxy in a rectangular shape measuring $120 \times 60 \times 20 \mathrm{~mm}$. The data logger could be programmed for a wide variety of sampling protocols. When sampling dive depth, swim speed, and stomach temperature every $10 \mathrm{~s}$, and water temperature every $60 \mathrm{~s}$, as in the application to Steller sea lions, the computer's 512 kbyte memory lasted $11.8 \mathrm{~d}$.

Satellite transmitter. The UHF satellite transmitter, also called a platform transmitting terminal (PTT), was based on a $0.4 \mathrm{~W}$ Telonics ST-6 in a low-density syntactic foam casting (Telonics, Mesa, AZ, USA). The PTT was powered by four $3.6 \mathrm{~V}$ lithium AA cells (SAFT LS14500) in series, with a capacity of $1.9 \mathrm{Ah}$ at $14.4 \mathrm{~V}$. The ST- 6 and batteries were encapsulated in Sealtronics epoxy in a rectangular form $(140 \times 70 \times$ $20 \mathrm{~mm}$ ), with the 2 emersion-sensing con- ductivity sensors (15 mm diam. stainless steel washers) placed on the surface in the centre of the front and back faces.

Buoyant data logger and PTT (BDLPTT) package. The data logger was bonded to the top surface of the PTT, and low-density syntactic foam was bonded to the sides and top of this combined unit (Fig. 2). A $200 \mathrm{lb}$ test, $1.75 \mathrm{~mm}$ diameter monofilament line was attached to the front surface to serve as the anchor line to the remote release device. A VHF beacon transmitter (Model SI-2sp, Holohil Systems, Carp, Ontario, Canada) was cast in syntactic foam in the shape of a cone and was bonded to the rear of the BDLPTT package (Fig. 2). The BDLPTT package weighed $660 \mathrm{~g}$ in air and had a positive buoyancy of $0.14 \mathrm{~N}$ in seawater. The centres of buoyancy and mass of this final package were adjusted so that it floated in seawater with the VHF antenna perpendicular to the water's surface, pointing skyward.

Remote-release system. This system consisted of a VHF triggering transmitter, an animal-mounted receiver/decoder, and an anchoring platform that relied

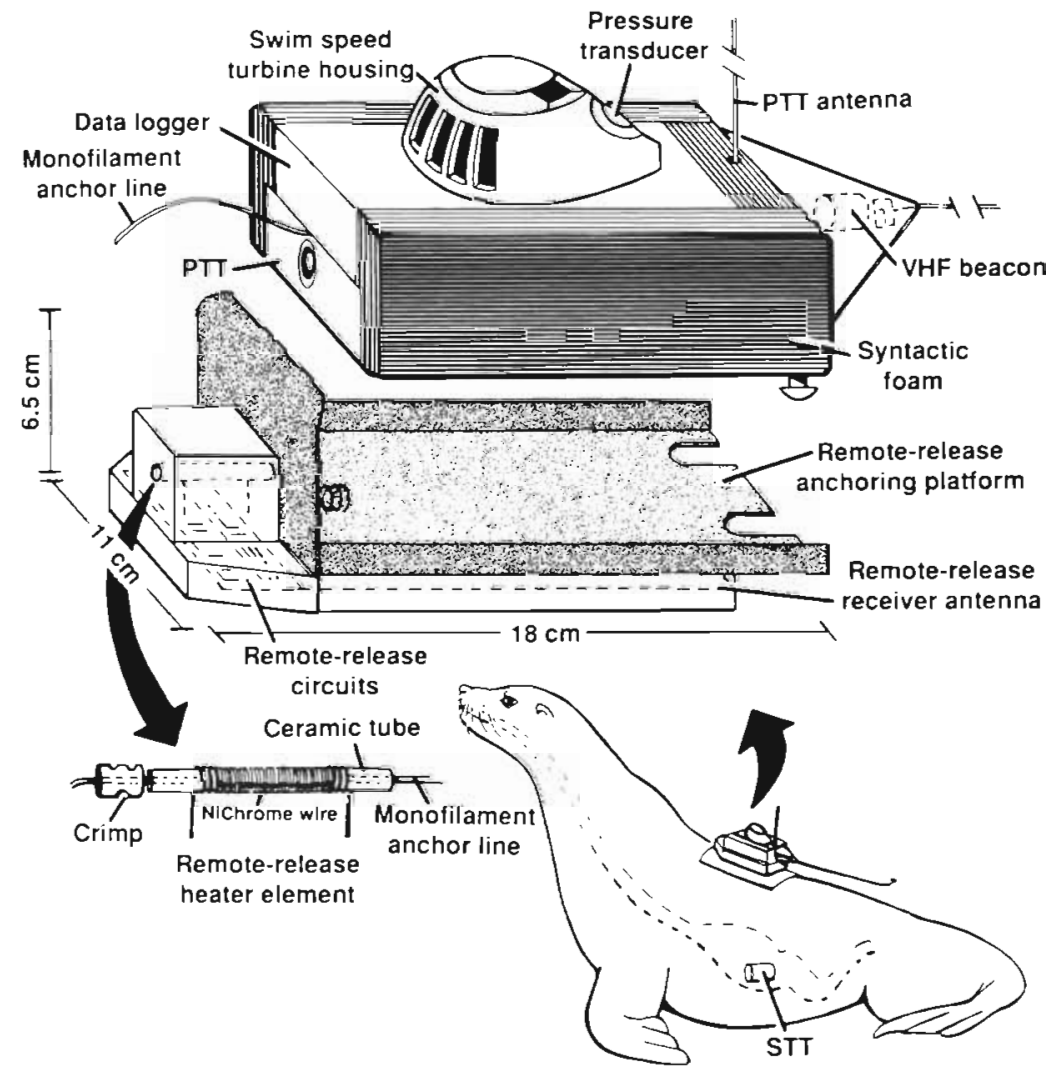

Fig. 2. Simplified diagram of the foraging behaviour monitoring system as applied to Steller sea lions, accompanied by an expanded view of the remote-release device and the data logger/PTT package. The remote-release heater element is also shown (bottom left) with the monofilament line secured by a crimp as it is when the data logger/PTT package is anchored in place 
on a heater element to melt and sever the monofilament anchor line. The AM transmitter (Model AttackSR, Futaba, Irvine, CA, USA) and receiver (Model FPR112JE, Futaba) were part of an off-the-shelf radio control (RC) system for model cars. In addition to low cost and wide availability, an advantage of this system is that each instrumented animal can have a separate remote-release frequency because of the interchangeable transmitter crystals. When the remote-release transmitter was turned on, the receiver produced an output at the servo jack consisting of $1.6 \mathrm{~ms}$ wide square-wave pulses repeating at $55 \mathrm{~Hz}$. This output was monitored by a custom decoding/release circuit based on an 8-bit microprocessor (PIC 16C71, Microchip Technology, Irvine, CA, USA) that was programmed to count the number of pulses that were within $\pm 20 \%$ of the average pulse width. If 25 acceptable pulses occurred within $0.5 \mathrm{~s}$, then the microprocessor signalled a logic-level power field-effecttransistor (FET) to open the current flow to the heater element. This process of monitoring the $\mathrm{RC}$ receiver output reduced the chance that the release would be accidentally triggered by any other type of transmitter operating on the same frequency band. The heater element (Alpha Omega Computer Systems, Corvallis, OR, USA) consisted of a ceramic tube wrapped with NiChrome wire and encapsulated in epoxy (Fig. 2). The heater element required approximately $25 \mathrm{~W}$ to melt and subsequently break a $200 \mathrm{lb}$ test monofilament line placed inside the ceramic tube. When immersed in $5^{\circ} \mathrm{C}$ water, the break takes about $10 \mathrm{~s}$ to complete. The power source for the heater element was 2 alkaline $9 \mathrm{~V}$ batteries in series. These batteries provided enough capacity to produce a line break in under $15 \mathrm{~s}$ for at least 10 repetitions, which allowed each sealed remote-release device to be tested before deployment.

The circuit boards and batteries for the remoterelease device were encapsulated in Sealtronics epoxy, creating a base for the anchoring platform (Fig. 2). The $0.3 \mathrm{~m} \mathrm{RC}$ receiver antenna was coiled around the periphery of this base, within the epoxy. An L-shaped stainless steel tray was mounted above the epoxy base. The anchoring platform weighed $730 \mathrm{~g}$ in air and had a negative buoyancy of $3.12 \mathrm{~N}$ in seawater Prior to deployment on a sea lion, the BDLPTT package was placed on the anchoring platform and the monofilament anchor line was drawn through the ceramic tube of the heater element. The package was held in place against the tension of 2 compressed stainless steel springs by fastening a copper compression sleeve, or crimp, on the monofilament line where it exited the heater element (Fig 2). When the remoterelease transmitter was activated within $75 \mathrm{~m}$ of the instrumented animal, the heater element melted and therefore severed the monofilament line, allowing the springs to push the BDLPTT package horizontally off the back of the anchoring platform.

Application and evaluation. Steller sea lions Eumetopias jubatus are found along the Pacific Rim from California to Japan, and 2 genetically distinct stocks have been identified (Hill et al. 1996). Although the population of the eastern stock, which ranges from California to just east of Prince William Sound $\left(144^{\circ} \mathrm{W}\right)$, is considered stable, the western stock (range: west of $144^{\circ} \mathrm{W}$ ) has declined by over $70 \%$ since 1980 (Hill et al. 1996, Trites \& Larkin 1996). It has been hypothesised that changes in prey availability have been a contributing factor to this population decline (Merrick et al. 1987). This hypothesis might be tested in a comparison of the foraging ecology of sea lions from the 2 different stocks, but first a method was needed to quantify foraging behaviour. This need led to the development of the equipment described above.

The STT system was tested in both laboratory stomach simulations and captive Steller sea lions. Although the details of these studies will be published separately, a brief synopsis is relevant here. Estimation of the quantity of ingested prey was complicated by many factors (e.g. body temperature and stomach heat flux changes, movement of the STT within the stomach, diverse prey size and shape, potentially concomitant water ingestion, and insulation of the STT by previously swallowed prey) and suffered a large margin of error. Determination of the timing of ingestion, however, was much more accurate, at least for the first few ingestion events in a bout of feeding In captive juvenile Steller sea lions, I could detect the initial ingestion of individual fish as small as $100 \mathrm{~g}$, which is near the average size of the fish consumed by wild sea lions (Calkins \& Goodwin 1988). Overall, the STT was quite similar in performance to the stomach temperature data loggers described by Wilson and colleagues (Wilson et al. 1992, 1995).

From the stable population in Southeast Alaska, on the Forrester Island rookery complex (Fig. 3), 6 Steller sea lions were instrumented with the system described above. Female sea lions with lactating pups were captured by darting with Telazol and anesthesia was maintained with isofluorane gas (Heath et al. 1996). The base of the remote-release device was glued to the pelage with 10 min epoxy and the STT was inserted into the stomach (Fig. 1). Sea lions were monitored using the VHF transmitter and the PTT, and after at least 1 foraging trip was completed remote release and recovery of the BDLPTT package was attempted

Successful release and recovery of 4 BDLPTT packages was accomplished after monitoring periods ranging from 4 to $7 \mathrm{~d}$. In 2 cases the packages were 

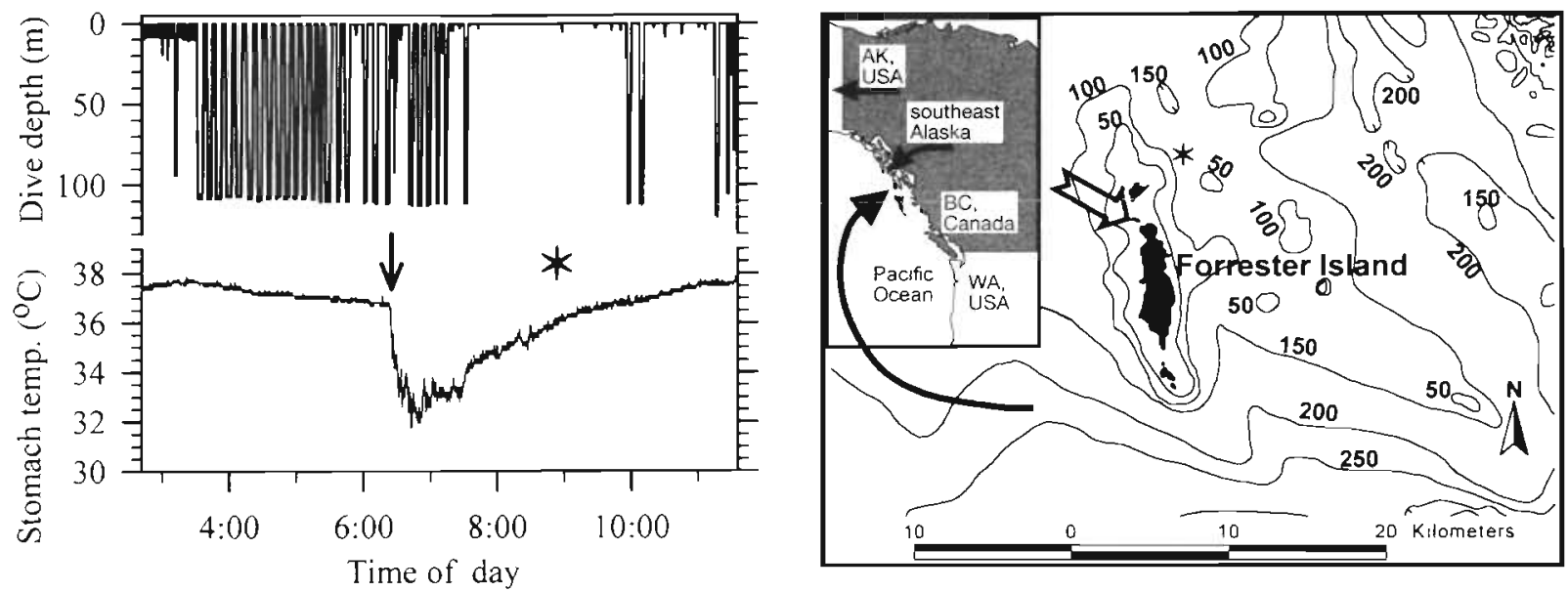

Fig. 3. Stomach temperature and dive depth (left) of a Steller sea lion on a foraging trip from the Forrester Island, Southeast Alaska, rookery (right: large, solid arrow marks location of Forrester Island on the inset map, open arrow marks rookery rocks). The precipitous drop in temperature $(\downarrow)$ is indicative of prey ingestion. On graph and map: (*) time and location, respectively, of a Class 1 quality Argos location fix. Comparison of maximum depths and bathymetry at that time and location suggests that this sea lion was foraging on the seabed

released and recovered on the rookery. The value of the buoyancy and the VHF beacon were demonstrated twice when packages were jettisoned off the edge of the rookery and recovered from the ocean. All 4 data loggers operated correctly and provided valuable data on Steller sea lion foraging behaviour. Exemplary data from 1 sea lion are shown in Fig. 3. By correlating the geographic location and the maximum dive depths around the time of the apparent ingestion event with bathymetric data, one can examine whether Steller sea lions are foraging on the seabed, a hypothesis supported by the predominance of benthic prey found in sea lion stomachs (Calkins \& Goodwin 1988).

The initial deployments of this stomach temperature transmitter and remotely releasable BDLPTT system have resulted in some improvements to the system. Two of the BDLPTT packages deployed on Steller sea lions fell off the remote release platform before remote release could be triggered. It appeared that the failure of the monofilament anchor line was caused by an application of extreme force to the side of the BDLPTT package. For increased protection, the stainless steel anchoring platform has been modified into an enclosed channel, open only at the front and back.

The original STT incorporated a relatively short titanium ring (to increase thermal conductance to the sensing thermistor; Fig. 1) because larger rings unacceptably reduced the transmission range. More powerful transmitters are now being built with a titanium sleeve that runs the entire length of the STT. Retention of the STT in the stomach is as problematic as retention of the ingestable data loggers has been in seabirds (Wilson et al. 1998). The records from the recovered instrument packs indicated that the STTs were lost before the end of the monitoring period in 3 out of 4 cases. The STTs were apparently regurgitated after 2.3 to $6.6 \mathrm{~d}$, but did allow the monitoring of between 1 and 2 complete foraging trips. In studies requiring longer monitoring periods it would be beneficial to modify the STT with a retention device as suggested by Wilson et al. (1998).

Other potential modifications include those designed to reduce the overall size and mass of the instruments. The remote-release device can be reduced in size in at least 2 ways. One is to reduce the battery capacity necessary to power the $\mathrm{RC}$ receiver by using the PIC microprocessor to monitor a pair of conductivity sensors and to only supply power to the receiver when the animal is potentially within range of the triggering transmitter (i.e. when at the water's surface or on land, but not when submerged). Another battery size reduction can be accomplished by reducing the amount of power needed to sever the monofilament anchor line. This could be achieved by using a smaller heater and thinner (lower test) monofilament line in situations where lower forces are encountered, or by wrapping the NiChrome wire directly onto the monofilament line. The latter method produces a strong anchor point, but, unlike the system using the ceramic insulating tube, each heater cannot be individually tested before deployment. The size of the BDLPTT package can be reduced by adding glass microbubbles to the epoxy encapsulating the data logger, thereby reducing the amount of external syntactic foam. Shape optimisation can be just as important as size reduction in decreasing the drag of the instruments, and therefore the final package should be as streamlined as possible (Bannasch et al. 1994). 
The instrumentation presented here is largely based on off-the-shelf components, which should encourage pinniped biologists or their local electrical/bioengineers to attempt its manufacture. The remoterelease system could easily be used with other types of monitoring devices, including commercially available TDRs. Although customised for monitoring pinnipeds, the instruments may also be suitable in modified form for studies of certain seabirds, sea turtles and cetaceans.

Acknowledgements. I thank Don Calkins and Andrew Trites for providing the opportunity to develop and apply this system to Steller sea lions, and all those at the Alaska Dept of Fish and Game, the Vancouver Public Aquarium, and elsewhere who helped with field and captive tests. Thanks are also due to Jeff Goodyear and Don Croll for advice on remoterelease (RR) devices, Ian Soutar for programming the RR PIC microprocessor, Mike Linse for designing the RR heater element, Tony Lum and Bruce Gillespie for design and construction help, Tara Law and Manfred Enstipp for reviewing an earlier draft of this manuscript and for participating in the development of these instruments. Vicky Earle for creating Fig. 2, and Professor Dave Jones for tolerating the diversion from m.y thesis research. This project was supported in part by Office of Naval Research Grant N00014-93-J-1680 and a grant from The North Pacific Marine Science Foundation through the North Pacific Universities Marine Mammal Research Consortium.

\section{LITERATURE CITED}

Andrews RD (1998) Instrumentation for the remote monitoring of physiological and behavioral variables. J Appl Physiol 85(5): 1974-1981

Baird RW, Goodyear JD (1993) An examination of killer whale diving behavior using a recoverable suction-cup attached TDR/VHF tag. In: Abstracts of the 10th Biennial Conference on the Blology of Marine Mammals. Soc Mar Mammology, Lawrence, KS, p 25

Bannasch R, Wilson RP, Culik B (1994) Hydrodynamic aspects of design and attachment of a back-mounted device in penguins. J Exp Biol 194:83-96

Bjorge A, Thompson D, Hammond P, Fedak M, Bryant $E_{\text {, }}$ Aarefjord $H_{1}$ Roen R, Olsen N (1995) Habitat use and diving behaviour of harbour seals in a coastal archipelago in Norway. In: Blix AS, Wallie L, Ultang $\varnothing$ (eds) Whales, seals, fish and man. Elsevier, Amsterdam, p 211-223

Calkins D, Goodwin E (1988) Investigation of the declining sea lion population in the Gulf of Alaska. Alaska Dept of Fish \& Game, Anchorage, AK

Ellis GM. Trites AW (1992) The RAM-packs came back: a method for attaching and recovering pinniped data recorders. Aquat Mamm 18:61-64

Emery KO (1941) Transportation of rock particles by seamammals. J Sediment Petrol 11:92-93

Editorial responsibility: Otto Kinne (Editor),

Oldendorf/Luhe, Germany
Gales R, Renouf D (1993) Detecting and measuring food and water intake in captive seals using temperature telemetry. $\mathrm{J}$ Wildl Manage 57(3):514-519

Heath RB, Calkins D, McAllister D, Taylor W, Spraker T (1996) Telazol and isoflurane field anesthesia in freeranging Steller's sea lions (Eumetopias jubatus). J Zoo Wildl Med 27:35-43

Hill. PS, DeMaster DP, Small RJ (1996) Alaska marine mammal stock assessments 1996. NOAA Tech Memo NMFSAFSC-78, US Department of Commerce, Washington, DC

Mackay RS (1964) Deep body temperature of untethered dolphin recorded by ingested radio transmitter. Science 144:864-866

Mackay RS (1966) Telemetering physiological information from within cetaceans, and the applicability of ultrasound to understanding in vivo structure and performance. In: Norris KS (ed) Whales, dolphins and porpoises. University of California Press, Berkeley, p 445-470

McGinnis SM, Whittow GC, Ohata CA, Huber H (1972) Body heat dissipation and conservation in two species of dolphins. Comp Biochem Physiol 43A:417-423

Merrick RL, Loughlin TR, Calkins DG (1987) Decline in abundance of the northern sea lion, Eumelopias jubatus, in Alaska, 1956-86. Fish Bull US 85:351-365

Norris KS, Evans WE, Ray GC (1974) New tagging and tracking methods for the study of marine mammal biology and migration. In: Schevill WE, Ray GC, Norris KS (eds) The whale problem, a status report. Harvard University Press Cambridge, MA, p 395-408

Ohata CA, Matsuura DT, Whittow GC, Tinker SW (1972) Diurnal rhythm of body temperature in the Hawaiian monk seal (Monachus schauinsland). Pac Sci 26:117-120

Tanaka H, Sato K, Matsuzawa Y, Sakamoto W, Naito Y, Kuroyanagi $K$ (1995) Analysis of possibility of feeding of loggerhead turtles during internesting periods based on stomach temperature measurements. Nippon Suisan Gakkaishi 61:339-345

Trites AW, Larkin PA (1996) Changes in the abundance of Steller sea lions (Eumetopias jubatus) in Alaska from 1956 to 1992: how many were there? Aquat Mamm 22:153-166

Wartzok D, Ray CG, Martin HB III (1975) A recording instrument package for use with marine mammals. Rapp PV Reun Cons Int Explor Mer 169:445-450

Westgate AJ, Read A.J, Berggren P, Koopman HN, Gaskin DE (1995) Diving behaviour of harbour porpoises, Phocoena phocoena. Can J Fish Aquat Sci 52:1064-1073

Whittow GC, Hampton IFG, Matsuura DT, Ohata CA, Smith RM, Allen JF (1974) Body temperature of three species of whales. J Marnm 55(3):653-656

Wilson RP, Cooper J, Plötz J (1992) Can we determine when marine endotherms feed? A case study with birds. J Exp Biol 167:267-275

Wilson RP. Pütz K, Grémillet D, Culik BM, Kierspel. M, Regel J, Bost CA, Lage J, Cooper J (1995) Reliability of stomach temperature changes in determining feeding characteristics of seabirds. J Exp Biol 198:1115-1135

Wilson R, Peters G, Regel J, Grémillet D, Pütz K, Kierspel M, Weimerskirch $H_{1}$ Cooper $J(1998)$ Short retention times of stomach temperafure loggers in free-living seabirds: is there hope in the spring? Mar Biol 130:559-566

Submitted: July 14, 1998; Accepted: October 28, 1998

Proofs received from author(s): November 30, 1998 